This item is the archived peer-reviewed author-version of:

\title{
Precipitation impacts on vegetation spring phenology on the Tibetan Plateau
}

\section{Reference:}

Shen Miaogen, Piao Shilong, Cong Nan, Zhang Gengxin, Janssens Ivan.- Precipitation impacts on vegetation spring phenology on the Tibetan Plateau

Global change biology - ISSN 1354-1013 - 21:10(2015), p. 3647-3656

Full text (Publishers DOI): http://dx.doi.org/doi:10.1111/gcb.12961

To cite this reference: http://hdl.handle.net/10067/1278290151162165141 


\section{Precipitation impacts on vegetation spring phenology on the Tibetan Plateau}

Running title: Spring phenology on Tibetan Plateau

1

2 Miaogen Shen ${ }^{1,2^{*}}$, Shilong Piao ${ }^{1,2}$, Nan Cong ${ }^{1}$, Gengxin Zhang $^{1}$, Ivan A Jassens ${ }^{3}$

3 1, Key Laboratory of Alpine Ecology and Biodiversity, Institute of Tibetan Plateau Research,

4 Chinese Academy of Sciences, 16 Lincui Road, Chaoyang District, Beijing, China

5 2, CAS Center for Excellence in Tibetan Plateau Earth Sciences, Beijing, China

6 3, Centre of Excellence PLECO (Plant and Vegetation Ecology), Department of Biology,

7 University of Antwerp, Wilrijk, Belgium

8

9 *Author for correspondence, Institute of Tibetan Plateau Research, Chinese Academy of 10 Sciences, No. 16 Lincui Rd., Chaoyang District, Beijing, 100101, China, Email:

11 shenmiaogen@itpcas.ac.cn, Tel: +8610-84097043, Fax: +8610-84097079 


\section{Abstract}

The ongoing changes in vegetation spring phenology in temperate/cold regions are widely attributed to temperature. However, in arid/semiarid ecosystems the correlation between spring temperature and phenology is much less clear. We test the hypothesis that precipitation plays an important role in the temperature dependency of phenology in arid/semi-arid regions.

We therefore investigated the influence of preseason precipitation on satellite-derived estimates of starting date of vegetation growing season (SOS) across the Tibetan Plateau (TP). We observed two clear patterns linking precipitation to SOS. First, SOS is more sensitive to inter-annual variations in preseason precipitation in more arid than in wetter areas. Spatially, an increase in long-term averaged preseason precipitation of $10 \mathrm{~mm}$ corresponds to a decrease of the precipitation sensitivity of SOS by about 0.01 day $\mathrm{mm}^{-1}$. Second, SOS is more sensitive to variations in preseason temperature in wetter than in dryer areas of the plateau. A spatial increase in precipitation of $10 \mathrm{~mm}$ corresponds to an increase in temperature sensitivity of SOS of 0.25 day ${ }^{\circ} \mathrm{C}^{-1}\left(0.25\right.$-day SOS advance per $1-{ }^{\circ} \mathrm{C}$ temperature increase).

Those two patterns indicate both direct and indirect impacts of precipitation on SOS on TP. This study suggest a balance between maximizing benefit from the limiting climatic resource and minimizing the risk imposed by other factors. In wetter areas, the lower risk of drought allows greater temperature sensitivity of SOS to maximize the thermal benefit, which is further supported by the weaker inter-annual partial correlation between growing degree days and preseason precipitation. In more arid areas, maximizing the benefit of water requires greater sensitivity of SOS to precipitation, with reduced sensitivity to temperature. This study highlights the impacts of precipitation on SOS in a large cold and arid/semiarid region and 
34 suggests that influences of water should be included in SOS module of terrestrial ecosystem 35 models for drylands.

36

37 Key words: climate change, precipitation, sensitivity, temperature, Tibetan Plateau, 38 vegetation spring phenology 


\section{Introduction}

The starting date of the vegetation growing season (SOS) in temperate and boreal regions has received particular attention, because of its strong response to climate change and its strong impacts on ecosystem processes, such as energy exchange, hydrological cycle, and carbon uptake (Badeck et al., 2004, Barr et al., 2009, Cleland et al., 2007, Obrist et al., 2003, Piao et al., 2007, Richardson et al., 2010, Richardson et al., 2013). Changes in SOS and their relation to the temperature rise during the past few decades have been well documented. For instance, Menzel et al. (2006) suggested that European phenology changes matched the ongoing warming pattern and Fu et al. (2014a) showed that the absence of further winter warming in recent years was reflected in homeostasis of spring phenology of early-spring species, while later-spring species continued to exhibit earlier leaf flushing in response to the continued warming trend in later spring.

Less attention has been devoted to the variability in the temperature dependency of SOS across a range of temperatures (Hwang et al., 2014, Penuelas et al., 2004). Recently, it was shown that the inter-annual relationships between temperature and SOS varied noticeably among different areas. For example, Jeong et al. (2011) found that the correlation coefficient between SOS and preseason mean temperature varied from -0.3 to -0.7 across the Northern Hemisphere, and that in central Eurasia faster warming did not necessarily induce greater SOS advance. Such a 'mismatch' was consistent with a recent study that indicated that the sensitivity of SOS to inter-annual variations in preseason mean temperature varied dramatically over the Northern Hemisphere (Shen et al., 2014a). The temperature sensitivity 
61 of vegetation spring phenology, defined as the change in SOS per unit change in 62 spring-temperature, is one of the most important keys to understanding the relationship between vegetation phenology and temperature change, and to project phenological changes in response to future climate change. However, the sensitivity of phenology to temperature change, and especially the regional differences in temperature sensitivity, is not yet fully understood.

While temperature plays an important role, other environmental factors may also affect SOS. Water is needed for sustaining plant growth, indicating that variability in SOS might be potentially related to optimal water conditions, particularly in the arid/semiarid areas. For example, Zhang et al. (2005) showed that the spatial variation in SOS closely tracked the onset of the rainy season in Africa, where temperature is a less limiting factor. In dry temperate/cold regions with wet winters, SOS may not be closely related to water conditions, because these tend to be optimal after winter. In contrast, in dry temperate/cold areas with dry winters and wetter summers, preseason precipitation determines water availability in spring and may therefore affect SOS (Chen et al., 2014). Hence, Cong et al. (2013) argued that the sensitivity of SOS to temperature was likely to be smaller in areas with less preseason precipitation in temperate China. In the temperate grasslands of Northeast China, green-up onset was indeed advanced during years with higher soil moisture (Liu et al., 2013). However, in a semiarid phenological garden (with an annual precipitation of $570 \mathrm{~mm}$ ) in central China with dry winters, leaf flushing was later after wetter winters than after drier winters in 34 out of 42 species ( 23 being significant at $\mathrm{P}<0.05$ level) and no single significantly negative 
correlation was observed between the first leafing date and the preseason precipitation (Dai et al., 2013). Moreover, it was reported that larger amounts of preseason precipitation may increase the heat demand (growing degree days) for SOS (Fu et al., 2014b), indicating that precipitation could exert other, indirect, impacts on spring phenology. The studies above suggest that preseason precipitation clearly can influence SOS, but also that there can be diverse responses of SOS to preseason precipitation even in arid/semiarid regions, rendering the sensitivity of SOS to preseason temperature even more complex.

Most areas of the Tibetan Plateau (TP) are characterized by an arid/semiarid climate, with annual precipitation ranging from dozens to hundreds of millimeters, and rainfall occurring mainly in the growing season from May to September (Gao \& Liu, 2013). Controversy still exists about the effects of precipitation on spring phenology on the TP. For example, Piao et al. (2006) suggested that increased preseason precipitation likely postponed SOS for alpine meadows and tundra in the TP, whereas Shen et al. (2014b) attributed delayed SOS to declines in preseason precipitation. The TP differs from the above reviewed dry temperate regions mainly because it is colder, with mean annual temperature ranging between $-15{ }^{\circ} \mathrm{C}$ and $10{ }^{\circ} \mathrm{C}$ (You et al., 2013). Variation in vegetation growth and in spring phenology is therefore strongly controlled by temperature (Kato et al., 2006, Piao et al., 2011, Tan et al., 2010, Wang et al., 2012). In this study, we aim to elucidate the effects of precipitation on inter-annual changes in SOS across the TP and on the response of SOS to temperature, and discuss the potential underlying mechanisms. 


\section{Materials and methods}

\section{Retrieving SOS using greenness vegetation index}

Greenness vegetation indices, including NDVI and enhanced vegetation index (EVI), have been shown sensitive indicators of canopy parameters, such as leaf area index and aboveground green biomass (Di Bella et al., 2004, Shen et al., 2008, Shen et al., 2010, Tucker et al., 1986, Wylie et al., 2002), and are therefore widely used to derive vegetation phenology (Ganguly et al., 2010, Garonna et al., 2014, Myneni et al., 1997, Shen et al., 2012, Zhang et al., 2013). We used NDVI derived from the observations by the sensor VEGETATION onboard Système Pour l'Observation de la Terre (SPOT NDVI) and MODerate resolution Imaging Spectroradiometer (MODIS NDVI and MODIS EVI) to determine SOS from 2000 to 2012 in the TP. We did not include the NDVI from Advanced Very High Resolution Radiometer (AVHRR), because it has been reported to have low quality on the western TP for this period (Zhang et al., 2013). The SPOT NDVI was produced at a spatial resolution of 1 $\mathrm{km}$ using the 10-day maximum-value composition technique (i.e., by selecting the highest NDVI value from each period of 10 days), and the MODIS NDVI and EVI were produced at 500-m resolution and 16-day compositing period. The effects of satellite orbit shift and sensor degradation have been removed and the atmospheric contaminations of water vapor, ozone and aerosols have also been eliminated, both following standard procedures (Huete et al., 2002, Maisongrande et al., 2004, Rahman \& Dedieu, 1994). Effects of snow cover on NDVI and EVI for each pixel were further eliminated by using the median value of the uncontaminated winter NDVI (EVI) values (MOD13A1-Quality, 2011, VGT-FAQ, 2012) between November and the following March (Ganguly et al., 2010, Zhang et al., 2006, Zhang 
et al., 2007). After that, abrupt drops of NDVI (EVI) value before the occurrence of the annual NDVI (EVI) maximum in summer were replaced by the value reconstructed using the Savitzky-Golay filter (Chen et al., 2004), because clouds and poor atmospheric conditions usually depress NDVI (EVI) values.

Next, four methods were used to determine SOS from the time series of each of the three vegetation indices, including two inflection point-based methods $\left(\mathrm{CCR}_{\max }\right.$ and $\left.\beta_{\max }\right)$ and two threshold-based methods $\left(\mathrm{G}_{20}\right.$ and $\left.\mathrm{CR}_{\max }\right)$. Taking NDVI as example, in the $\mathrm{CCR}_{\max }$ method, SOS was determined as the date when the rate of change of curvature of the logistic function curve fitted to NDVI reaches its first local maximum value (Zhang et al., 2003). In the $\beta_{\max }$ method, SOS was calculated as the date when NDVI increases at the highest rate in a year (Studer et al., 2007). In the $\mathrm{G}_{20}$ method, SOS was the first day in the ascending period when NDVI increased above $20 \%$ of its annual range (Yu et al., 2010). When applying the $\mathrm{RC}_{\max }$ method, SOS was the date when NDVI first reaches a predefined absolute threshold that corresponds to the maximum rate of changes in the average seasonal NDVI curve in spring (Piao et al., 2006). Detailed descriptions of those four methods are given in Shen et al. (2014b). We calculated the temporal trend of SOS determined for each method and vegetation index using linear regression between SOS and year order, and found a broadly consistent spatial pattern of trends across all the vegetation indices and methods [similar to Fig. 4 in Shen et al. (2014b)]. We hence used averaged SOS over all the three vegetation indices and four methods in the following analyses. 
Analyses

Considering that both preseason precipitation and temperature may affect SOS, its sensitivity to preseason mean temperature (Ta) and to cumulative precipitation (PPT) was defined respectively as the coefficients of Ta and PPT using the multiple linear regression in which SOS was set the dependent variable and Ta and PPT the independent variables for each pixel. Since the length of the preseason period for Ta or PPT could vary among different areas (Jeong et al., 2011, Shen et al., 2011), we did not use a fixed period. Instead, we used an optimization method to determine the preseason period length for Ta and PPT for each pixel using a linear regression. In the optimization process, we minimized the root mean of squared errors (RMSE) between observed and predicted SOS by using Ta and PPT for periods of different lengths preceding the 2000-2012 average of SOS. Here, a step of 10 days was used when changing the preseason period length to smooth potential extreme values. We did not constrain that the preseason length for Ta is identical to that for PPT. After having determined the optimal preseason length for each pixel, preseason temperature and precipitation, and the sensitivity of SOS to these climatic variables were determined. For each pixel, we used the preseason precipitation averaged for 2000-2012 to present its preseason water availability, i.e., areas with more long-term average precipitation were considered wetter.

\section{We next investigated whether or not precipitation would indirectly affect SOS by altering the} heat requirement of plant seasonal development. The heat requirement is expressed in growing degree days (GDD), which is a widely used method to assess the effect of temperature on plant development (e.g.Botta et al., 2000, Chuine, 2000, Fu et al., 2014b, 
171 Hanninen \& Kramer, 2007, Jeong et al., 2012, Zhang et al., 2007). We analyzed the effect

172 of precipitation on GDD using the inter-annual partial correlation between the preseason

173 precipitation and GDD and setting the number of chilling days (CD) as the control variable.

174 The latter was done to remove the potential effects of CD on GDD, because previous studies

175 showed a negative correlation between GDD and CD (Murray et al., 1989, Zhang et al., 2004).

176 This partial correlation method has been successfully applied to remove the covariate effects

177 between multiple influential factors in ecological studies (Beer et al., 2010, Fu et al., 2014b,

178 Peng et al., 2013). Here, GDD was the sum of daily mean temperature exceeding $0{ }^{\circ} \mathrm{C}$ from

179 January $1^{\text {st }}$ to the day before SOS. CD was the number of days with daily mean temperature 180 below $0{ }^{\circ} \mathrm{C}$ from September $1^{\text {st }}$ in the previous year to SOS.

181

To examine whether or not SOS is more sensitive to preseason temperature in wetter than in dryer areas, spatial partial correlation analysis was conducted between the temperature sensitivity of SOS and the long-term average precipitation data, while setting mean annual temperature (MAT) over 2000-2012 and mean CD over 2000-2012 as the control variables. In parallel, spatial partial correlation analysis was performed between precipitation sensitivity of SOS and the long-term average precipitation, again while accounting for MAT and CD. We also investigated the spatial variability in the precipitation effect on the heat requirement in relation to water condition. This was achieved using spatial partial correlation between the inter-annual partial correlation coefficient between the preseason precipitation and GDD and the long-term average precipitation, with MAT and CD being the control variables. Last, we applied spatial partial correlation analysis between GDD and the long-term average 
193

194

195

196

197

198

199

200

201

202

203

204

205

206

207

208

209

210

211

212

213

214

precipitation accounting for MAT and $\mathrm{CD}$, to examine whether or not GDD requirement is higher in wetter areas.

The above analyses were conducted twice, first on all pixels across the plateau and second on only those pixels that were equipped with a meteorological station, which occurred predominantly in the eastern and central parts of the TP (Fig. 1b). For these latter station-level analyses, we used daily temperature and precipitation records from 1999 to 2012 for 80 meteorological stations across the TP, which were provided by the China Meteorological Administration (CMA, http://cdc.cma.gov.cn/index.jsp). For the TP-wide analyses on all pixels, daily temperature and precipitation were calculated from a dataset developed by the Data Assimilation and Modeling Center for Tibetan Multi-spheres, Institute of Tibetan Plateau Research, Chinese Academy of Sciences (Chen et al., 2011, He, 2010). The data were produced at a temporal resolution of 3 hours and spatial resolution of $0.1^{\circ} \times 0.1^{\circ}$, covering the entire mainland of China. Air temperature at $1.5 \mathrm{~m}$ was produced by merging the observations collected at 740 operational stations of CMA into the corresponding Princeton meteorological forcing data (Sheffield et al., 2006). Precipitation was produced by combining three datasets, including the Tropical Rainfall Measuring Mission (TRMM) 3B42 precipitation products (Huffman et al., 2007), precipitation observations from 740 operational stations of CMA, and the Asian Precipitation - Highly Resolution Observational Data Integration Toward Evaluation of the Water Resources (APHRODITE) precipitation data (Yatagai et al., 2009).

\section{Results}


Spatial distribution of sensitivity of SOS to preseason temperature and precipitation

The temperature sensitivity of SOS, determined by a multiple regression, was negative in approximately $77 \%$ of the $\mathrm{TP}$ area, especially in the central, eastern, and northeastern parts (Fig. 1a). This temperature sensitivity was significantly negative $(\mathrm{P}<0.05, \mathrm{~T}$-test $)$ in about $37 \%$ of the pixels. The temperature sensitivity exceeded (was lower than) -4 day ${ }^{\circ} \mathrm{C}^{-1}$, i.e. an increase in preseason temperature of $1^{\circ} \mathrm{C}$ corresponded to a SOS advance of at least 4 days, in nearly $39 \%$ of the area. In contrast to this majority of pixels exhibiting the expected advance of SOS with warming, much less positive temperature sensitivities were observed (Fig. 1a, right bottom inset). These occurred mainly in the southwestern plateau and in a few areas in the west and southwest of the Qinghai Lake and southeastern plateau. These positive temperature sensitivities ranged from 0 to +6 day ${ }^{\circ} \mathrm{C}^{-1}(95 \%$ percentile $)$ and were significantly positive $(\mathrm{P}<0.05)$ for only about $5 \%$ of the pixels. A briefly similar spatial pattern was also found for the temperature sensitivities of SOS calculated using the weather station data (Fig. 1b).

The precipitation sensitivity of SOS showed a strikingly different spatial pattern. In the southwestern plateau, the majority of pixels exhibited negative sensitivity values, mostly lower than -0.1 day $\mathrm{mm}^{-1}$, i.e. an increase in preseason precipitation of $10 \mathrm{~mm}$ corresponded to a SOS advance of at least 1 day (Fig. 2a). Increases in preseason precipitation were also likely to advance SOS in northeastern parts and a few of the central parts of the TP. In total, about $69 \%$ of the pixels showed negative precipitation sensitivity values, $23 \%$ being significant $(\mathrm{P}<0.05)$. On the other hand, positive precipitation sensitivity values were found 
237 in about $31 \%$ of the TP; $5 \%$ being statistically significant $(\mathrm{P}<0.05)$, occurring mostly in the central plateau. The precipitation sensitivity calculated using weather station data also showed a roughly similar spatial pattern (Fig. $2 b)$.

Spatial variations in temperature and precipitation sensitivity of SOS in relation to climatic precipitation gradient

We observed that, in general, SOS was more sensitive to inter-annual changes in preseason mean temperature in the wetter areas (i.e., with higher long-term average precipitation) (Fig. 3a). Spatially, an increase in long-term average precipitation of $10 \mathrm{~mm}$ corresponded to an increase in temperature sensitivity of 0.25 day ${ }^{\circ} \mathrm{C}^{-1}$. The spatial variations in temperature sensitivity with regard to long-term average precipitation showed a similar pattern when we only included the pixels with a temperature sensitivity significant at $\mathrm{P}<0.05$ level (grey line in Fig. 3a). Moreover, a significantly negative $(\mathrm{P}<0.01)$ spatial correlation between temperature sensitivity and long-term average precipitation was also found in a partial correlation analysis of the weather station observations in which MAT and CD were corrected for (Fig. 3a, left inset).

On the other hand, the precipitation sensitivity of SOS generally decreased from -0.14 day $\mathrm{mm}^{-1}$ in the most arid area (receiving only $25 \mathrm{~mm}$ precipitation) to 0 day $\mathrm{mm}^{-1}$ in the areas with a long-term average precipitation of $150 \mathrm{~mm}$ or more (Fig. 3b). On average, an increase in long-term average precipitation of $10 \mathrm{~mm}$ corresponded to an increase in precipitation sensitivity of 0.01 day $\mathrm{mm}^{-1}$ within the areas with the precipitation ranging from $25 \mathrm{~mm}$ to 
$150 \mathrm{~mm}$. The precipitation sensitivity variations also showed a similar decreasing pattern with regard to multi-yearly averaged precipitation when we only considered precipitation sensitivity significant at $\mathrm{P}<0.05$ level (grey line in Fig. 3b). Further, the partial correlation analysis on the pixels with meteorological stations confirmed that the precipitation sensitivity of SOS weakens with increasing preseason precipitation ( $\mathrm{P}<0.01$; Fig. 3b, inset).

\section{Relationship between GDD and precipitation}

Because of the clear relationship between preseason precipitation and the temperature sensitivity of SOS, we further investigated the inter-annual relationship between GDD and precipitation by performing a partial correlation analysis. As shown in Fig. 4a, the partial correlation was negative for $76 \%$ of the pixels across the TP, except for a few areas in the east of the plateau center. In particular in the southwestern plateau, the majority of the correlations was lower than $-0.6(\mathrm{P}<0.05)$. Significantly negative correlations were also found in many areas in the southeastern and northeastern plateau. Only about $2 \%$ of the pixels exhibited significantly positive $(\mathrm{P}<0.05)$ correlations. A similar spatial pattern of the partial correlations was found when analyzing the weather station data (Fig. 4b).

The partial correlation between preseason precipitation and GDD was generally stronger (more negative) for areas with less precipitation, increasing from -0.4 (on average) in areas with long-term average precipitation of about $25 \mathrm{~mm}$ to around -0.15 in areas with a long-term precipitation of about $150 \mathrm{~mm}$ (Fig. 4c). Above this precipitation threshold, the correlation coefficient was very low, between -0.1 to 0 (Fig. 4c). Indeed, statistically 
281

282

283

284

285

286

287

288

289

290

291

292

293

294

295

296

297

298

299

300

301

302

significant (at $\mathrm{P}<0.05$ ) partial correlation coefficients between GDD and precipitation were almost not observed in areas with more than $150 \mathrm{~mm}$ precipitation. Also across the weather stations, the partial correlation coefficient between GDD and precipitation tended to be stronger for areas with less precipitation $(\mathrm{P}<0.05$; Fig. 4c, inset).

We also explored whether or not there was a spatial correlation between GDD and long-term averaged precipitation. To do this, we first calculated the average GDD over 2000-2012 for each pixel. As shown in Fig. 5a, average GDD was higher in the southwestern, southeastern, and northeastern parts of plateau, ranging from 200 to $500{ }^{\circ} \mathrm{C}$-days ( $95 \%$ percentile) and was lower in the plateau center, mostly lower than $200{ }^{\circ} \mathrm{C}$-days. Spatially, the GDD was lower in areas with less precipitation, decreasing from about $340{ }^{\circ} \mathrm{C}$-days at a long-term average precipitation of $25 \mathrm{~mm}$ to about $150{ }^{\circ} \mathrm{C}$-days at $150 \mathrm{~mm}$ (Fig. $5 \mathrm{~b}$ ), which is consistent with the negative inter-annual correlation between GDD and precipitation reported above. The weather stations-based analysis also revealed that the average GDD was spatially negatively related to long-term average precipitation $(\mathrm{R}=-0.55, \mathrm{P}<0.01)$ in the partial correlation between them by setting MAT and CD as controlling variables.

\section{Precipitation impact on SOS of different vegetation types}

On average, the alpine vegetation (including alpine tundra, alpine cushion, and alpine sparse vegetation; Editorial Board of Vegetation Map of China CAS (2001)) received the highest long-term average precipitation $(90 \mathrm{~mm})$, and had the highest temperature sensitivity of SOS

$\left(-3.3\right.$ day $\left.{ }^{\circ} \mathrm{C}^{-1}\right)$, the lowest precipitation sensitivity of SOS $\left(-0.024\right.$ day $\left.\mathrm{mm}^{-1}\right)$, the weakest 
inter-annual partial correlation between GDD and preseason precipitation $(-0.18)$, and the lowest GDD ( $155^{\circ} \mathrm{C}$-days) among the three vegetation types (Fig. 6). In contrast, the steppe vegetation showed the exact opposite pattern, with the lowest long-term average precipitation (72 $\mathrm{mm})$, the lowest temperature sensitivity of $\operatorname{SOS}\left(-1.9\right.$ day $\left.{ }^{\circ} \mathrm{C}^{-1}\right)$, the greatest precipitation sensitivity of SOS $\left(-0.108\right.$ day $\left.\mathrm{mm}^{-1}\right)$, the strongest inter-annual partial correlation between GDD and preseason precipitation (-0.44), and the highest GDD $\left(213{ }^{\circ} \mathrm{C}\right.$-days $)$. The third vegetation type, the meadows, received intermediate long-term average precipitation and exhibited intermediate values for the SOS-related variables too. Moreover, we found a similar pattern of the impacts of precipitation on SOS and its responses to the preseason climatic factors among the three vegetation types, when only focusing on the pixels with significant (P $<0.05)$ sensitivities or partial correlations. Here we assume that the vegetation types do not change very much during the period of 2000-2012.

\section{Discussion}

Previous studies on phenology responses to climate warming in the TP have consistently shown SOS advances of about 2 weeks in the 1980s and 1990s (Piao et al., 2011, Yu et al., 2010, Zhang et al., 2013). Increasing spring temperature has been recognized as the major determinant of these SOS advances on the TP (Piao et al., 2011, Shen et al., 2014b). However, the potential impact of preseason precipitation was ignored in these previous studies. During 2000-2011, despite continued spring warming, there has been no further regionally consistent advancing trend of SOS, with contrasting SOS patterns among the different areas of plateau (Shen et al., 2014b). In this study, we used multivariate linear regression to incorporate the 
effects of both preseason temperature and precipitation on SOS. The results indicated that, for a considerable area in southwestern TP, spring warming coincided with delayed SOS (Fig. 1).

Moreover, across most of the TP, especially in the southwestern and northeastern plateau, increased preseason precipitation coincided with advanced SOS (Fig. 2).SOS on the TP is thus affected by both preseason temperature and precipitation, yielding spatially diverse SOS responses to climate change. Hence, analyses conducted at a regionally-aggregated level can not elucidate the real impacts of climate change on the SOS in the TP. Our results of the spatial pattern of SOS response to preseason temperature and precipitation may be taken to suggest that the regional-scale SOS advance in the 1980s and 1990s was likely the result of the combination of increasing temperature (Piao et al., 2006) and fairly stable precipitation (Piao et al., 2012, Xu et al., 2008). In contrast, during 2000-2011 the decline in precipitation and further increase in temperature (Shen et al., 2014b) did not significantly alter regional-level SOS during this period.

We observed that SOS sensitivity to both preseason temperature and precipitation varies greatly across the TP, with preseason precipitation affecting both these sensitivities. Water availability is thus an important determinant of the spatial pattern of SOS responses to climate change. In wetter areas, vegetation growth initiation is not limited by lack of water, and thus SOS can respond to temperature with greater sensitivity than to precipitation. In such areas, larger amounts of preseason precipitation would not advance SOS, but the accompanying deficient sunshine intensity and duration may retard SOS, either directly or indirectly by causing lower temperatures. In contrast, in more arid areas, soil moisture may still be 
sub-optimal after winters with low rainfall, possibly explaining why SOS was less sensitive to temperature and more to preseason precipitation. Moreover, high preseason temperatures in these arid areas could even reduce water availability by increasing evapotranspiration and may thus even delay SOS (Yu et al., 2003), explaining the unexpected positive temperature sensitivities of SOS that we observed for these dry regions in our analysis.

The current pattern of SOS sensitivity suggests that the TP vegetation tends to maximize the climatic benefit by making best use of climatic factors and meanwhile minimize the climatic risks. In wetter areas, where the risk of drought is lower, vegetation may have developed a greater temperature sensitivity of SOS to maximize the thermal benefit, a hypothesis that is further supported by the weaker inter-annual partial correlation between GDD and precipitation in those areas. In more arid areas, maximizing the usage of water (preseason precipitation) results in greater sensitivity of SOS to precipitation. We speculate that plants initiate their growth earlier if soil moisture becomes optimal earlier (more rainfall), even if temperatures are less optimal; in contrast, plants postpone SOS when soil moisture is still sub-optimal (low rainfall), even if GDD requirements have already been met.

To facilitate the greater precipitation sensitivity of SOS in dryer areas, heat should not be a limiting resource. For the mechanisms in the previous paragraph to function, vegetation in more arid areas should exhibit higher GDD requirements and a stronger negative inter-annual partial correlation between GDD and precipitation (i.e. greater GDD in years with less precipitation). The higher GDD requirement has the additional advantage of reducing the frost 
369

370

371

372

373

374

375

376

377

378

379

380

381

382

383

384

385

386

387

388

389

390

risk. Hence, we hypothesize that there is a balance between maximizing the benefit from the limiting climatic resource and minimizing the risk imposed by other factors.

This study is the first to quantify the impacts of precipitation on SOS in one of the world's largest cold regions. Our results suggest that the projected warmer and slightly wetter future climate (IPCC, 2007) may generally favor earlier SOS on the TP. Meanwhile, attention should be paid to drought that could delay SOS and thus cause net carbon loss in warmer springs as ecosystem respiration can be elevated by higher temperature (Tan et al., 2010). On the other hand, SOS delay of the grasslands could lead to foliage deficiency for yak and sheep and thus the local nomad's well-being (Klein et al., 2014), highlighting the need of forecasting grassland SOS which could be improved by incorporating effects of precipitation.

Drylands cover about $41 \%$ of Earth's land surface (Reynolds et al., 2007). For the arid/semiarid regions with dry and cold winter, such as the TP and north China (but probably also many other regions on Earth), both preseason temperature and precipitation affect SOS, leading to a complex response of SOS to climate change. For these regions, the impacts of precipitation on SOS and on the SOS sensitivity to temperature should also be accounted for while assessing the vegetation phenological responses to climate change. If the conclusions obtained from this study are transferable to other winter-dry regions of the Earth, climatic warming may lead to greater SOS advance in relatively wetter areas than in dryer areas. Alternatively, in dry areas, especially where precipitation is not projected to increase, climatic warming may have smaller impact on SOS and might even delay SOS in the long term since 
391 evapotranspiration may increase and permafrost may degrade (two processes that can 392 decrease water availability). In addition, intra-seasonal changes in the timing and frequency of 393 precipitation could also lead to SOS shifts. The impacts of precipitation on SOS are currently 394 not included in the GDD- and/or CD-based phenology modules embedded in the 395 state-of-the-art terrestrial biosphere models (Richardson et al., 2012) that are used by the 396 397 Intergovernmental Panel on Climate Change (IPCC), which may be a source of uncertainty in phenology model projections for drylands.

\section{Acknowledgements}

This work is funded by a "Strategic Priority Research Program (B)" of the Chinese Academy of Sciences (Grant No. XDB03030404), a National Basic Research Program of China (Grant No. 2013CB956303), and a grant from the National Natural Science Foundation of China (No. 41201459). I.A.J. acknowledges support from the European Research Council Synergy grant 610028. three contrasting boreal forest ecosystems in Western Canada, Heidelberg, Springer. 
413

414

415

416

417

418

419

420

421

422

423

424

425

426

427

428

429

430

431

432

433

434

Botta A, Viovy N, Ciais P, Friedlingstein P, Monfray P (2000) A global prognostic scheme of leaf onset using satellite data. Global Change Biology, 6, 709-725.

Chen J, Jonsson P, Tamura M, Gu ZH, Matsushita B, Eklundh L (2004) A simple method for reconstructing a high-quality NDVI time-series data set based on the Savitzky-Golay filter. Remote Sensing Of Environment, 91, 332-344.

Chen XQ, Li J, Xu L, Liu L, Ding D (2014) Modeling greenup date of dominant grass species in the Inner Mongolian Grassland using air temperature and precipitation data. International Journal of Biometeorology, 58, 463-471.

Chen Y, Yang K, He J, Qin J, Shi J, Du J, He Q (2011) Improving land surface temperature modeling for dry land of China. Journal of Geophysical Research, 116.

Chuine I (2000) A unified model for budburst of trees. Journal of Theoretical Biology, 207, 337-347.

Cleland EE, Chuine I, Menzel A, Mooney HA, Schwartz MD (2007) Shifting plant phenology in response to global change. Trends in Ecology \& Evolution, 22, 357-365.

Cong N, Wang T, Nan H, Ma Y, Wang X, Myneni RB, Piao S (2013) Changes in satellite-derived spring vegetation green-up date and its linkage to climate in China from 1982 to 2010: a multi-method analysis. Global Change Biology, 19, 881-891.

Dai JH, Wang HJ, Ge QS (2013) Multiple phenological responses to climate change among 42 plant species in Xi'an, China. International Journal of Biometeorology, 57, 749-758.

Di Bella C, Faivre R, Ruget F et al. (2004) Remote sensing capabilities to estimate pasture production in France. International Journal of Remote Sensing, 25, 5359-5372.

Editorial Board of Vegetation Map of China Cas (2001) 1:1000,000 Vegetation Atlas of China. (ed Hou XY) pp Page, Beijing, China, Science Press. 
435

Fu Y, Piao S, Op De Beeck M, Cong N, Menzel A, Janssens IA (2014a) Recent spring phenology shifts in Central Europe based on multi-scale observations. Global Ecology and Biogeography, In Press, DOI: 10.1111/geb.12210.

Fu YH, Piao S, Zhao H et al. (2014b) Unexpected role of winter precipitation in determining heat requirement for spring vegetation green-up at northern-middle and high latitudes. Global Change Biology, In Press, doi: 10.1111/gcb.12610.

Ganguly S, Friedl MA, Tan B, Zhang XY, Verma M (2010) Land surface phenology from MODIS: Characterization of the Collection 5 global land cover dynamics product. Remote Sensing Of Environment, 114, 1805-1816.

Gao YC, Liu MF (2013) Evaluation of high-resolution satellite precipitation products using rain gauge observations over the Tibetan Plateau. Hydrology and Earth System Sciences, 17, 837-849.

Garonna I, De Jong R, De Wit AJW, Mücher CA, Schmid B, Schaepman M (2014) Strong contribution of autumn phenology to changes in satellite-derived growing season length estimates across Europe (1982-2011). Global Change Biology, In Press, doi: 10.1111/gcb.12625.

Hanninen H, Kramer K (2007) A framework for modelling the annual cycle of trees in boreal and temperate regions. Silva Fennica, 41, 167-205.

He J (2010) Development of surface meteorological dataset of China with high temporal and spatial resolution. Unpublished M. S. Chin. Acad. of Sci.,, Beijing, China.

Huete A, Didan K, Miura T, Rodriguez EP, Gao X, Ferreira LG (2002) Overview of the radiometric and biophysical performance of the MODIS vegetation indices. Remote Sensing Of Environment, 83, 195-213.

Huffman GJ, Adler RF, Bolvin DT et al. (2007) The TRMM multisatellite precipitation analysis (TMPA): Quasi-global, multiyear, combined-sensor precipitation estimates at fine scales. Journal of 
Hydrometeorology, 8, 38-55.

458

459

460

461

462

463

464

465

466

467

468

469

470

471

472
Hwang T, Band LE, Miniat CF, Song C, Bolstad PV, Vose JM, Love JP (2014) Divergent phenological response to hydroclimate variability in forested mountain watersheds. Global Change Biology, 20, 2580-2595.

Ipcc (2007) Climate Change 2007: The physical science basis, New York, Cambridge University Press.

Jeong S-J, Ho C-H, Gim H-J, Brown ME (2011) Phenology shifts at start vs. end of growing season in temperate vegetation over the Northern Hemisphere for the period 1982-2008. Global Change Biology, 17, 2385-2399.

Jeong SJ, Medvigy D, Shevliakova E, Malyshev S (2012) Uncertainties in terrestrial carbon budgets related to spring phenology. Journal of Geophysical Research-Biogeosciences, 117, doi: 10.1029/2011jg001868.

Kato T, Tang YH, Gu S, Hirota M, Du MY, Li YN, Zhao XQ (2006) Temperature and biomass influences on interannual changes in $\mathrm{CO} 2$ exchange in an alpine meadow on the Qinghai-Tibetan Plateau. Global Change Biology, 12, 1285-1298.

Klein JA, Hopping KA, Yeh ET, Nyima Y, Boone RB, Galvin KA (2014) Unexpected climate impacts on the Tibetan Plateau: Local and scientific knowledge in findings of delayed summer. Global Environmental Change, 28, 141-152.

Liu H, Tian F, Hu HC, Hu HP, Sivapalan M (2013) Soil moisture controls on patterns of grass green-up in Inner Mongolia: an index based approach. Hydrology and Earth System Sciences, 17, 805-815.

Maisongrande P, Duchemin B, Dedieu G (2004) VEGETATION/SPOT: an operational mission for the Earth monitoring; presentation of new standard products. International Journal of Remote Sensing, 25, 9-14.

Menzel A, Sparks TH, Estrella N et al. (2006) European phenological response to climate change matches the warming pattern. Global Change Biology, 12, 1969-1976.

Mod13a1-Quality

(2011)

MOD13A1

VI

Quality.

$\mathrm{pp}$

Page, 
https://lpdaac.usgs.gov/products/modis_products_table/mod13a1.

Murray M, Cannell M, Smith R (1989) Date of budburst of fifteen tree species in Britain following climatic warming. Journal of Applied Ecology, 26, 693-700.

Myneni RB, Keeling CD, Tucker CJ, Asrar G, Nemani RR (1997) Increased plant growth in the northern high latitudes from 1981 to 1991. Nature, 386, 698-702.

Obrist D, Verburg PSJ, Young MH, Coleman JS, Schorran DE, Arnone JA (2003) Quantifying the effects of phenology on ecosystem evapotranspiration in planted grassland mesocosms using EcoCELL technology. Agricultural and Forest Meteorology, 118, 173-183.

Peng S, Piao S, Ciais P et al. (2013) Asymmetric effects of daytime and night-time warming on Northern Hemisphere vegetation. Nature, 501, 88-92.

Penuelas J, Filella I, Zhang XY et al. (2004) Complex spatiotemporal phenological shifts as a response to rainfall changes. New Phytologist, 161, 837-846.

Piao S, Cui M, Chen A, Wang X, Ciais P, Liu J, Tang Y (2011) Altitude and temperature dependence of change in the spring vegetation green-up date from 1982 to 2006 in the Qinghai-Xizang Plateau. Agricultural and Forest Meteorology, 151, 1599-1608.

Piao S, Fang JY, Zhou LM, Ciais P, Zhu B (2006) Variations in satellite-derived phenology in China's temperate vegetation. Global Change Biology, 12, 672-685.

Piao S, Tan K, Nan H et al. (2012) Impacts of climate and CO2 changes on the vegetation growth and carbon balance of Qinghai-Tibetan grasslands over the past five decades. Global and Planetary Change, 98-99, 73-80.

Piao SL, Friedlingstein P, Ciais P, Viovy N, Demarty J (2007) Growing season extension and its impact on terrestrial carbon cycle in the Northern Hemisphere over the past 2 decades. Global Biogeochemical 
501

502

503

504

505

506

507

508

509

510

511

512

513

514

515

516

517

518

519

520

521

522

Cycles, 21, GB3018, doi:3010.1029/2006GB002888.

Rahman H, Dedieu G (1994) SMAC - a simplified method for the atmospheric correction of satellite measurements in the solar spectrum. International Journal of Remote Sensing, 15, 123-143.

Reynolds JF, Smith DM, Lambin EF et al. (2007) Global desertification: building a science for dryland development. Science, 316, 847-851.

Richardson AD, Anderson RS, Arain MA et al. (2012) Terrestrial biosphere models need better representation of vegetation phenology: results from the North American Carbon Program Site Synthesis. Global Change Biology, 18, 566-584.

Richardson AD, Black AT, Ciais P et al. (2010) Influence of spring and autumn phenological transitions on forest ecosystem productivity. Philosophical Transactions of the Royal Society B: Biological Sciences, 365, 3227-3246.

Richardson AD, Keenan TF, Migliavacca M, Ryu Y, Sonnentag O, Toomey M (2013) Climate change, phenology, and phenological control of vegetation feedbacks to the climate system. Agricultural and Forest Meteorology, 169, 156-173.

Sheffield J, Goteti G, Wood EF (2006) Development of a 50-year high-resolution global dataset of meteorological forcings for land surface modeling. Journal of Climate, 19, 3088-3111.

Shen M, Tang Y, Chen J, Yang W (2012) Specification of thermal growing season in temperate China from 1960 to 2009. Climatic Change, 114, 793-798.

Shen M, Tang Y, Chen J et al. (2014a) Earlier-Season Vegetation Has Greater Temperature Sensitivity of Spring Phenology in Northern Hemisphere. PLOS ONE, 9, e88178.

Shen M, Tang Y, Chen J, Zhu X, Zheng Y (2011) Influences of temperature and precipitation before the growing season on spring phenology in grasslands of the central and eastern Qinghai-Tibetan Plateau. 
524

525

526

527

528

529

530

531

532

533

534

535

536

537

538

539

540

541

542

543

Shen M, Tang Y, Klein J, Zhang P, Gu S, Shimono A, Chen J (2008) Estimation of aboveground biomass using in situ hyperspectral measurements in five major grassland ecosystems on the Tibetan Plateau. Journal of Plant Ecology, 1, 247-257.

Shen M, Zhang G, Cong N, Wang S, Kong W, Piao S (2014b) Increasing altitudinal gradient of spring vegetation phenology during the last decade on the Qinghai-Tibetan Plateau. Agricultural and Forest Meteorology, 189-190, 71-80.

Shen MG, Chen J, Zhu XL, Tang YH, Chen XH (2010) Do flowers affect biomass estimate accuracy from NDVI and EVI? International Journal of Remote Sensing, 31, 2139-2149.

Studer S, Stockli R, Appenzeller C, Vidale PL (2007) A comparative study of satellite and ground-based phenology. International Journal of Biometeorology, 51, 405-414.

Tan K, Ciais P, Piao S et al. (2010) Application of the ORCHIDEE global vegetation model to evaluate biomass and soil carbon stocks of Qinghai-Tibetan grasslands. Global Biogeochem. Cycles, 24, GB1013.

Tucker CJ, Fung IY, Keeling CD, Gammon RH (1986) Relationship between Atmospheric CO2 Variations and a Satellite-Derived Vegetation Index. Nature, 319, 195-199.

Vgt-Faq (2012) FAQ About the VGT products. pp Page, http://www.vgt.vito.be/faqnew/.

Wang S, Duan J, Xu G et al. (2012) Effects of warming and grazing on soil N availability, species composition, and ANPP in an alpine meadow. Ecology, 93, 2365-2376.

Wylie BK, Meyer DJ, Tieszen LL, Mannel S (2002) Satellite mapping of surface biophysical parameters at the biome scale over the North American grasslands - A case study. Remote Sensing Of Environment, 79, 266-278.

544 Xu ZX, Gong TL, Li JY (2008) Decadal trend of climate in the Tibetan Plateau-regional temperature and 
precipitation. Hydrological Processes, 22, 3056-3065.

546

547

548

Yatagai A, Arakawa O, Kamiguchi K, Kawamoto H, Nodzu MI, Hamada A (2009) A 44-Year Daily Gridded Precipitation Dataset for Asia Based on a Dense Network of Rain Gauges. Sola, 5, 137-140.

You QL, Fraedrich K, Ren GY, Pepin N, Kang SC (2013) Variability of temperature in the Tibetan Plateau based on homogenized surface stations and reanalysis data. INTERNATIONAL JOURNAL OF CLIMATOLOGY, 33, 1337-1347.

Yu FF, Price KP, Ellis J, Shi PJ (2003) Response of seasonal vegetation development to climatic variations in eastern central Asia. Remote Sensing Of Environment, 87, 42-54.

Yu HY, Luedeling E, Xu JC (2010) Winter and spring warming result in delayed spring phenology on the Tibetan Plateau. Proceedings of the National Academy of Sciences of the United States of America, 107, 22151-22156.

Zhang G, Zhang Y, Dong J, Xiao X (2013) Green-up dates in the Tibetan Plateau have continuously advanced from 1982 to 2011. Proceedings of the National Academy of Sciences of the United States of America, $110,4309-4314$.

Zhang X, Friedl MA, Schaaf CB et al. (2003) Monitoring vegetation phenology using MODIS. Remote Sensing Of Environment, 84, 471-475.

Zhang XY, Friedl MA, Schaaf CB (2006) Global vegetation phenology from Moderate Resolution Imaging Spectroradiometer (MODIS): Evaluation of global patterns and comparison with in situ measurements. Journal of Geophysical Research-Biogeosciences, 111, G04017, doi:04010.01029/02006JG000217.

Zhang XY, FriedI MA, Schaaf CB, Strahler AH (2004) Climate controls on vegetation phenological patterns in northern mid- and high latitudes inferred from MODIS data. Global Change Biology, 10, 1133-1145.

Zhang XY, FriedI MA, Schaaf CB, Strahler AH, Liu Z (2005) Monitoring the response of vegetation phenology to 
567 precipitation in Africa by coupling MODIS and TRMM instruments. Journal of Geophysical Research-Atmospheres, 110, D12103, 12110.11029/12004JD005263

569

Zhang XY, Tarpley D, Sullivan JT (2007) Diverse responses of vegetation phenology to a warming climate.

570 Geophysical Research Letters, 34, L19405, doi:19410.11029/12007GL031447.

571

572

573 


\section{$574 \quad$ Figure captions}

575

576

577 Spatial distribution of sensitivity of SOS to preseason mean temperature (day ${ }^{\circ} \mathrm{C}^{-1}$ ). (a), the

Fig. 1 sensitivity was calculated for each pixel using satellite-derived SOS and temperature and 579 precipitation developed by Data Assimilation and Modeling Center for Tibetan Multi-spheres, Institute of Tibetan Plateau Research, Chinese Academy of Sciences. Top inset shows the pixels with significantly $(\mathrm{P}<0.05)$ negative (green) and positive (red) sensitivities. The bottom right inset shows the frequency distributions of corresponding sensitivity. Grey indicates no SOS data. (b), similar to (a), but using temperature and precipitation observed at meteorological stations.

Fig. 2

Similar to Fig. 1, but for sensitivity of SOS to preseason precipitation (day $\mathrm{mm}^{-1}$ ).

Fig. 3

(a) Variations in sensitivity of SOS to preseason mean temperature along the spatial gradient of long-term average precipitation. The black thick curve shows the values averaged from all the pixels for each 10-mm bin of long-term average precipitation, and the gray thick curve shows the average of sensitivity significant at $\mathrm{P}<0.05$ level. Error bar shows standard error of the mean (SEM). The partial correlation coefficient near the black thick curve was between the temperature sensitivity of SOS and long-term average precipitation while accounting for 
596 CD and MAT. The right inset shows the frequency distributions of corresponding long-term 597 average precipitation. The left inset shows the spatial partial correlation coefficient between

598

599

600

601

602

603

604

605

606

607

608

609

610

611

612

613

614

615

616

617

Fig. 4

(a) Spatial distribution of inter-annual partial correlation coefficient between GDD and preseason precipitation with setting $\mathrm{CD}$ as the controlling variable. The inset shows the frequency distributions of corresponding correlation coefficient. Correlation coefficient values of $\pm 0.5, \pm 0.58, \pm 0.71$ correspond to significance levels of $\mathrm{P}=0.10,0.05$, and 0.01 , respectively. (b) Similar to (a), but using temperature and precipitation observed at meteorological stations. (c) Variations in the inter-annual partial correlation coefficient along the spatial gradient of long-term average precipitation. The black thick curve shows the values averaged from all the pixels for each 10-mm bin of long-term average precipitation, and the gray thick curve shows the average of partial correlation coefficient significant at $\mathrm{P}<0.05$ level. The partial correlation coefficient near the black thick curve was between the inter-annual partial correlation coefficient between GDD and preseason precipitation and long-term average precipitation while accounting for CD and MAT. Error bar shows SEM. The inset shows the spatial partial correlation coefficient between inter-annual partial correlation coefficient between GDD and precipitation and long-term average precipitation by 
618 setting MAT and CD at the controlling variables, using temperature and precipitation 619 observed at meteorological stations. *** and ** indicate significance at $\mathrm{P}<0.01$ and $\mathrm{P}<0.05$ 620 levels, respectively.

621

622 Fig. 5

623

(a) Spatial distribution of multi-yearly averaged GDD $\left({ }^{\circ} \mathrm{C}\right.$ day). The inset shows the frequency distributions of corresponding GDD. (b) The black thick curve shows variations in multi-yearly averaged GDD and the gray curve shows the MAT along the spatial gradient of long-term average precipitation. Error bar shows SEM. The partial correlation coefficient near the black thick curve was between GDD and long-term average precipitation while accounting for $\mathrm{CD}$ and MAT. The inset shows the spatial partial correlation between multi-yearly averaged GDD and long-term average precipitation by setting MAT and CD as the controlling variables, using temperature and precipitation observed at meteorological stations. ${ }^{* * *}$ indicates significance at $\mathrm{P}<0.01$ level.

Fig. 6

Comparisons of averages of long-term average precipitation, sensitivities of SOS to preseason mean temperature and precipitation, inter-annual partial correlation coefficient between GDD and precipitation, and multi-yearly averaged GDD, among the three major vegetation types of the Tibetan Plateau. The solid curves show the values averaged from all the pixels for each vegetation type, and the dashed curves show the average of significant $(\mathrm{P}<0.05)$ items listed 639 in the right $y$-axis labels. Alpine veg includes alpine tundra, alpine cushion, and alpine sparse 
640 vegetation according to Editorial Board of Vegetation Map of China CAS (2001).

641 

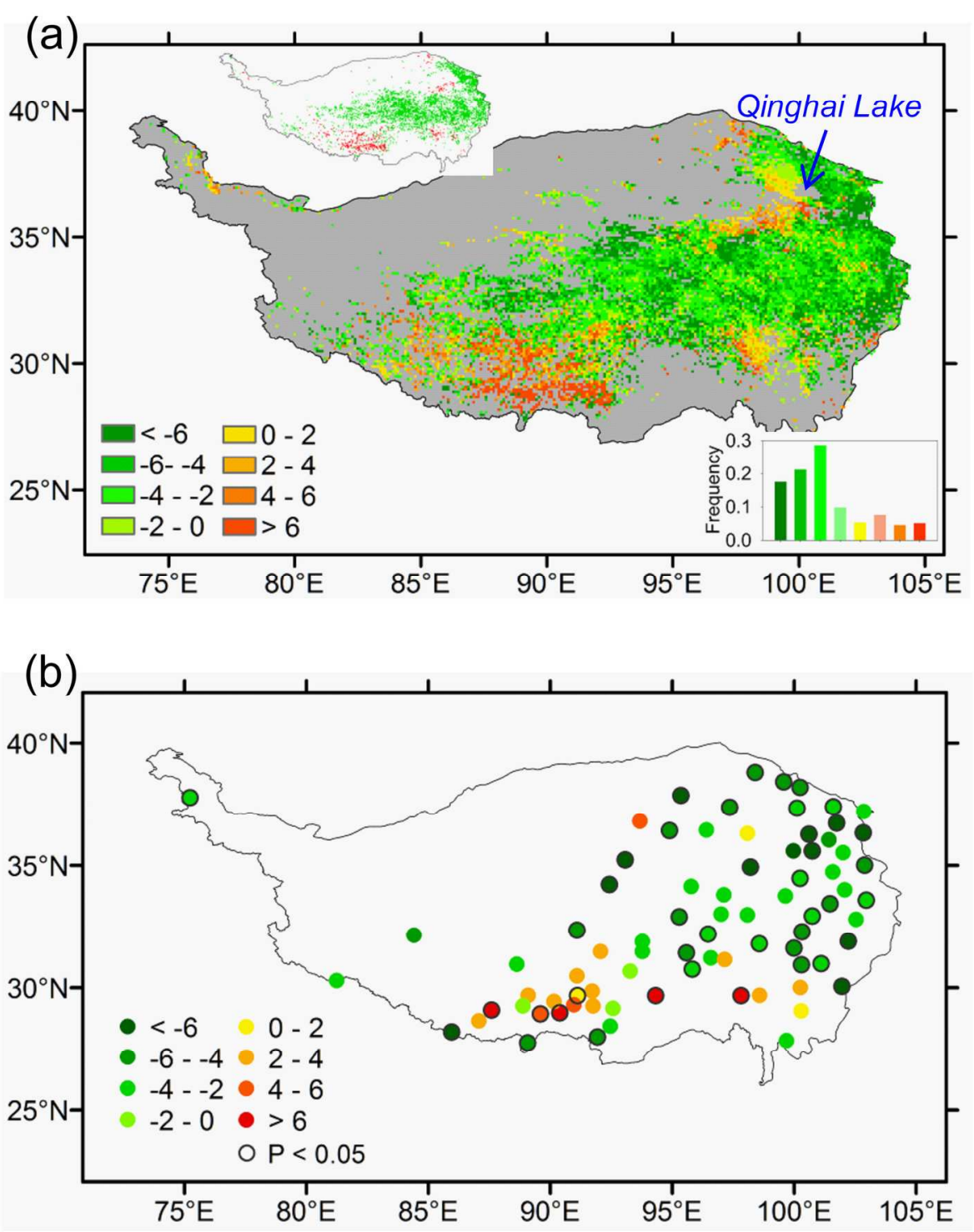

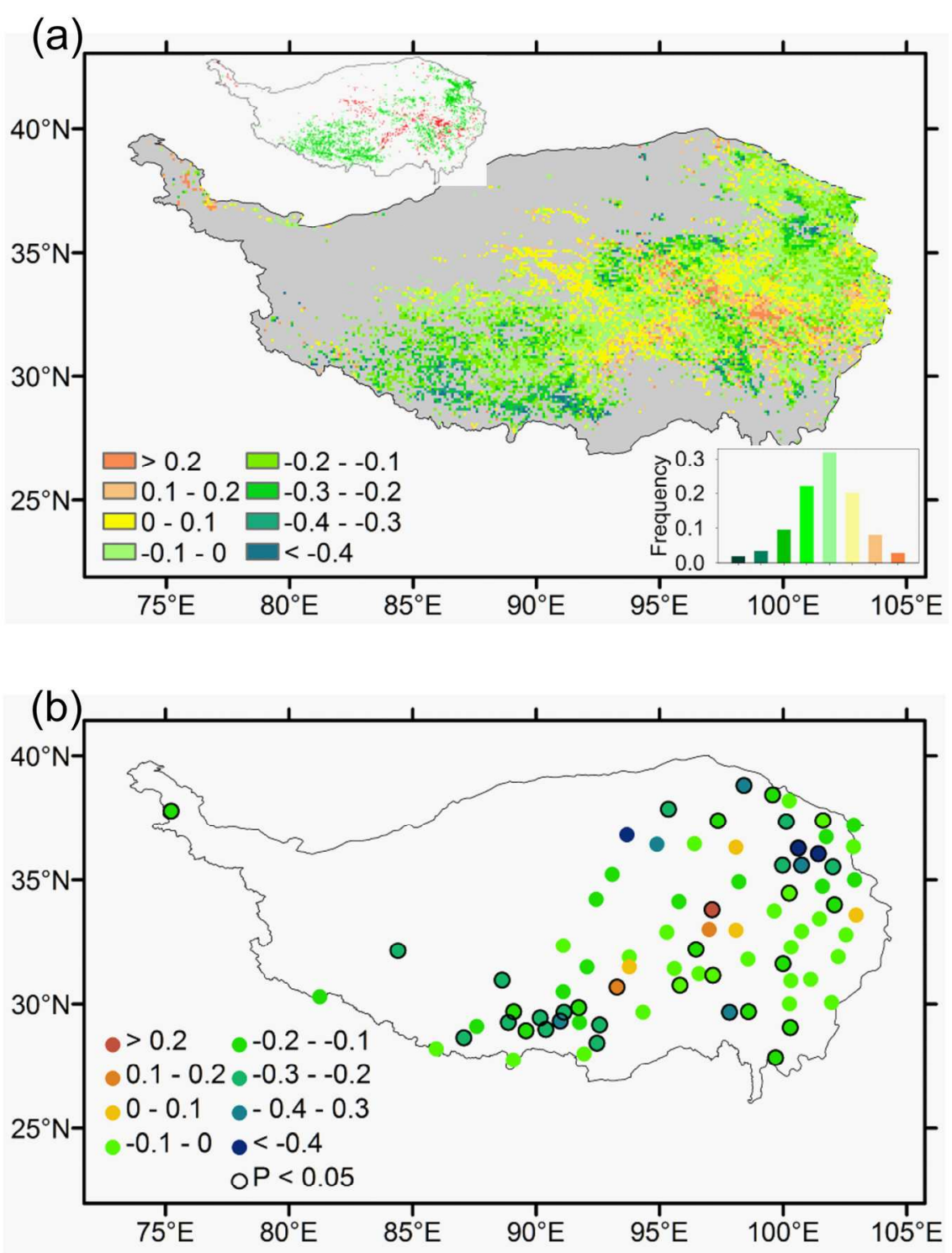

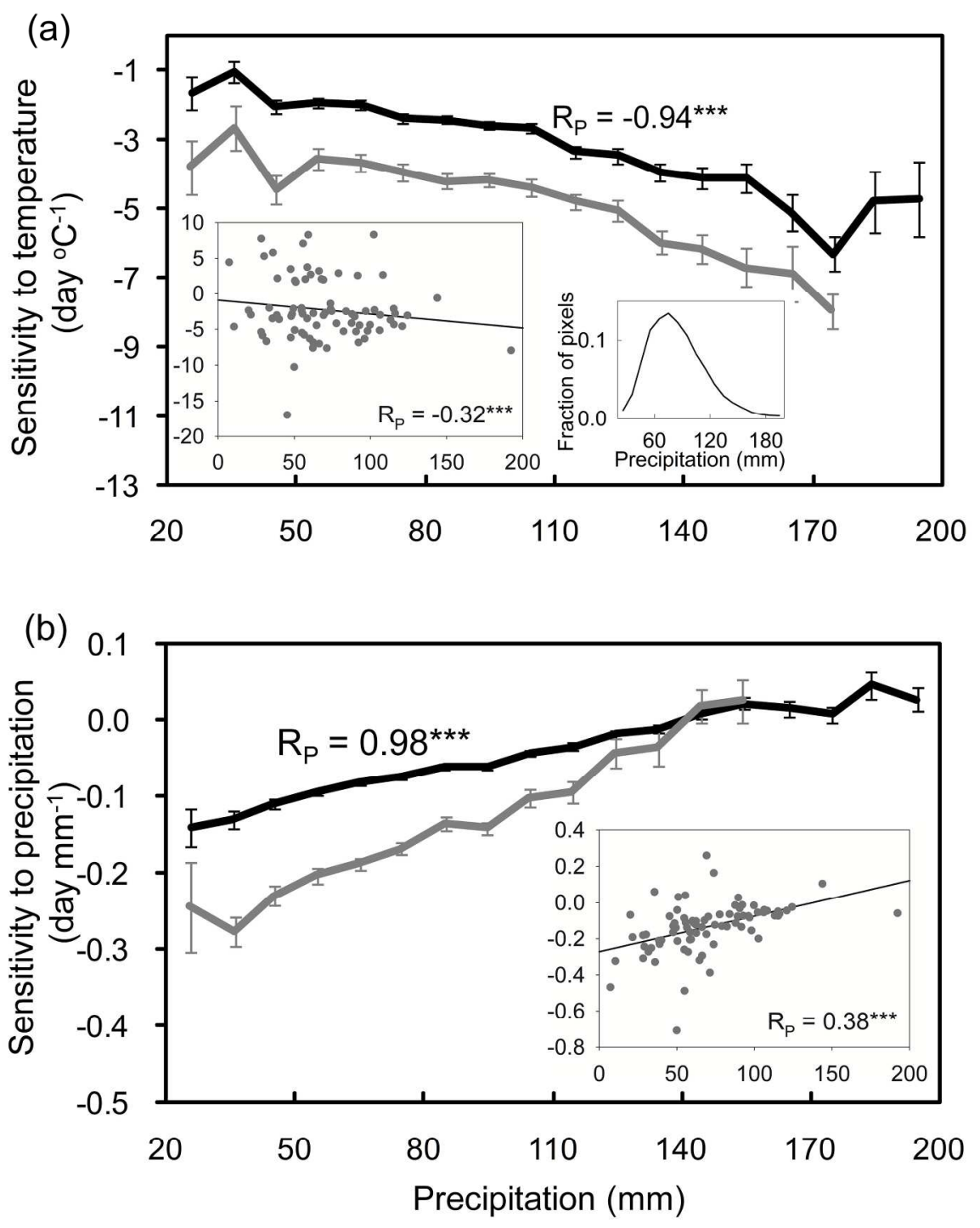

$203 \times 258 \mathrm{~mm}(300 \times 300 \mathrm{DPI})$ 

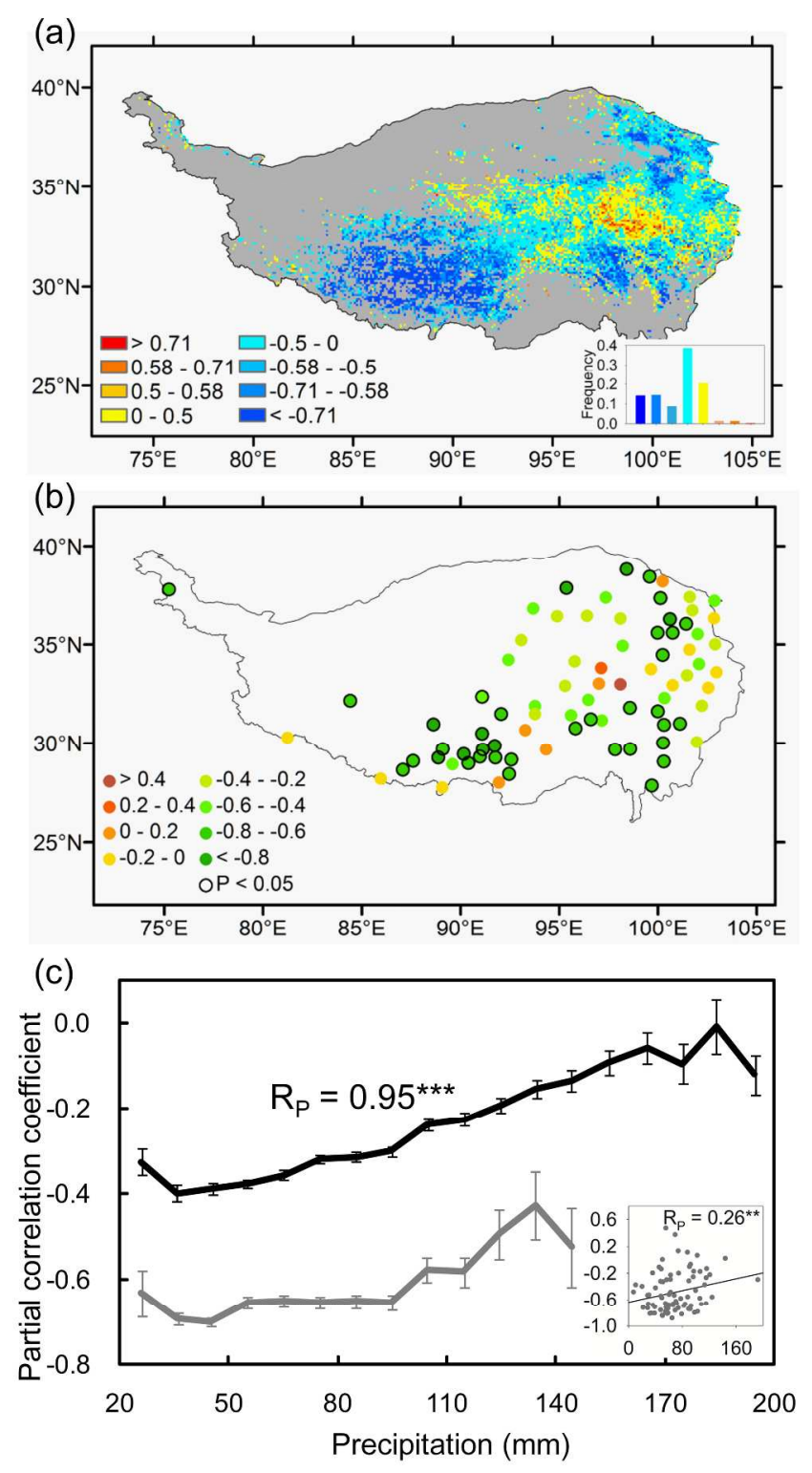

$238 \times 423 \mathrm{~mm}(300 \times 300$ DPI $)$ 
(a)

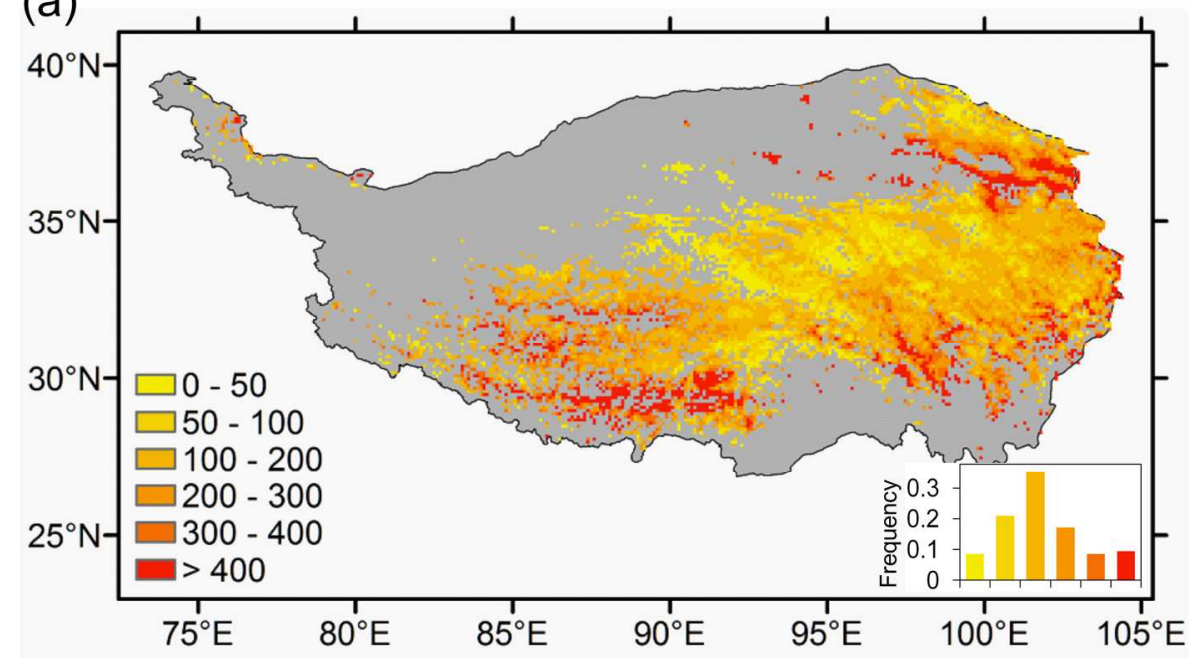

(b)

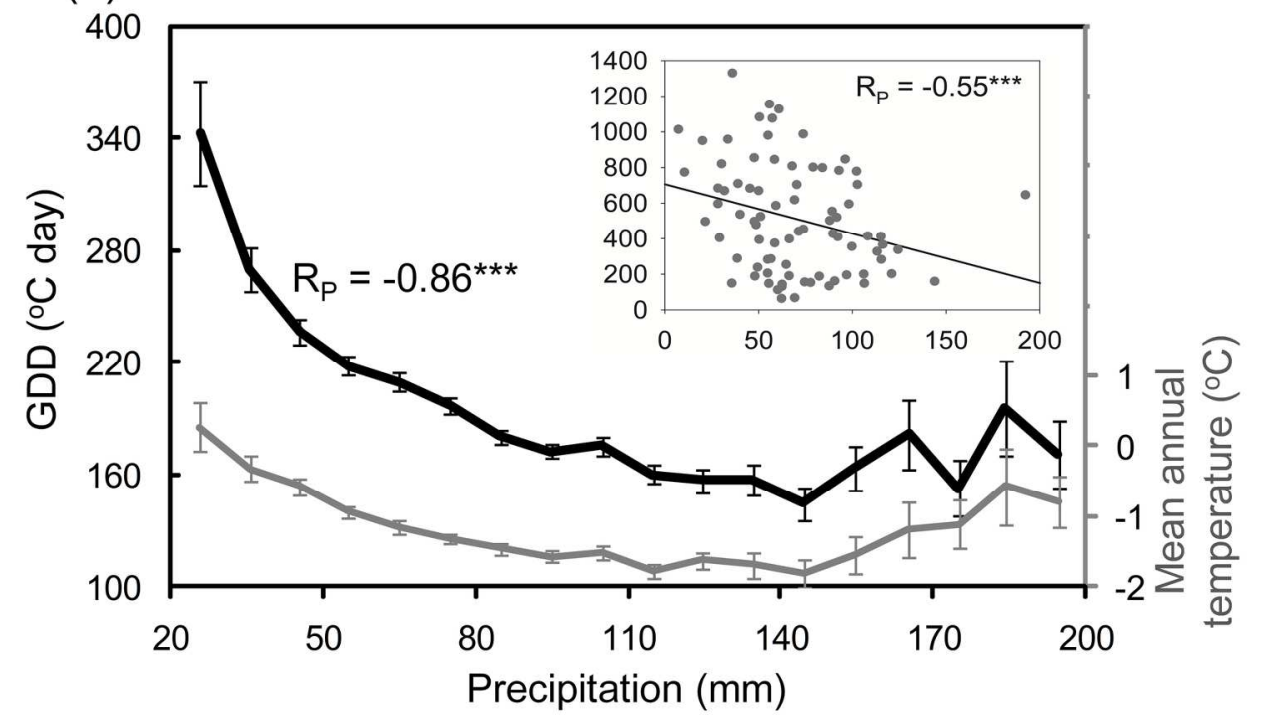

$184 \times 219 \mathrm{~mm}(300 \times 300$ DPI $)$ 


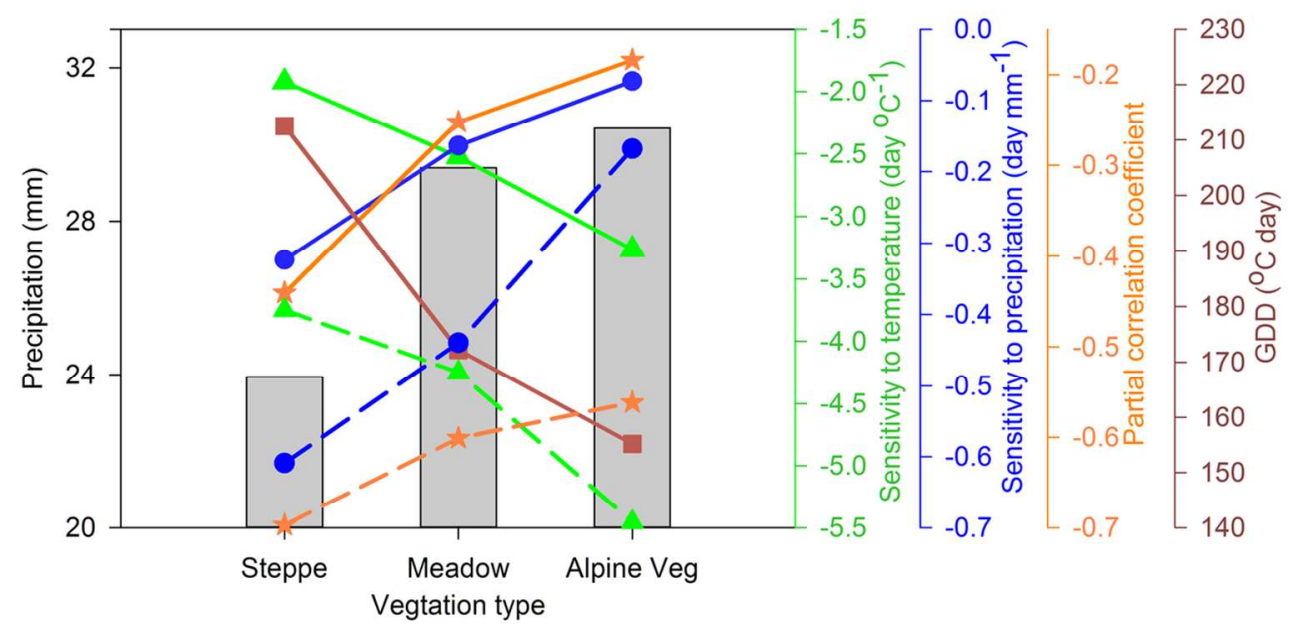

$114 \times 55 \mathrm{~mm}(300 \times 300$ DPI $)$ 